\title{
Francis Hutcheson, da beleza à perspectiva do desígnio
}

\author{
Lisa Broussois
}

Paris I Panthéon-Sorbonne

Tadução: Leonardo Paes Müller 

This Beauty arising from Correspondence to Intention, would open to curious Observers a new Scene of Beauty in the works of NATURE, by considering how the Mechanism of the various Parts known to us seems adapted to the Perfection of that Part, and yet in Subordination to the Good of some System or Whole. ${ }^{1}$

Francis Hutcheson (1725/26, p. 40)

\section{Introdução: Investigação sobre as nossas ideias da beleza e da virtude}

Francis Hutcheson publicou em 1725 sua Investigação sobre as nossas ideias da beleza e da virtude. Essa obra é composta por dois tratados, nos quais, segundo o próprio subtítulo da obra, ele defende e explica os princípios de Lord Shaftesbury contra o autor da Fábula das Abelhas, Bernard Mandeville. O primeiro tratado apresenta a tese da existência de um senso de beleza nos seres humanos. É a parte da Investigação destinada à "beleza, ordem, harmonia e desígnio". O segundo tratado desenvolve sua teoria a respeito da existência de um senso moral e se intitula "Investigação sobre a origem de nossas ideias do bem e do mal morais". No

1 Ver nota 19, abaixo. As edições da Investigação de Francis Hutcheson utilizadas foram as seguintes: Hutcheson, Recherche sur l'origine de nos idées de la beauté et de la vertu. Anne-Dominique Balmès (traduction française). Paris: Vrin, 1991 e em inglês: Hutcheson, An inquiry into the original of our ideas of beauty and virtue; Alterations and additions made in the second edition ot the "Inquiry into beauty and virtue". Londres: J. Darby, for W. and J. Smith, 1725/1726; Hutcheson, An essay on the nature and conduct of the passions and affections (Ensaio sobre a natureza e a conduta das paixões e afecções). Londres: J. Darby and T. Browne, for J. Smith and W. Bruce, 1728 e Hutcheson, A Short Introduction to Moral Philosophy (Curta introdução à filosofia moral). Glasgow: R. Foulis, 1747. O título completo da primeira edição da Investigação é: An Inquiry into the Original of our Ideas of Beauty and Virtue; in Two Treatises in which The Principles of the Late Earl of Shaftesbury are Explain'd and Defended, against the Author of the Fable of the Bees: and the Ideas of Moral Good and Evil are establish'd, according to the Sentiments of the Ancient Moralists. With an Attempt to introduce a Mathematical Calculation in Subjects of Morality. Ou seja: "Investigação sobre a origem de nossas ideias de beleza e virtude em dois tratados, nos quais são explicados e defendidos os princípios do falecido Conde de Shafesbury contra o autor da Fábula das abelhas, e as ideias de bem e mal morais são definidas de acordo com os sentimentos dos moralistas antigos. Com uma tentativa de introduzir um cálculo matemático em objetos morais" (Hutcheson, 1991, p. 8-9). 
primeiro tratado, Hutcheson desenvolve sua teoria propriamente estética, mesmo que à época o termo ainda não seja empregado nesse sentido. ${ }^{2}$ Esse tratado demonstra que a beleza é uma ideia que nasce da percepção das qualidades reais em relação no objeto. Toda a questão consiste, primeiro, em identificar quais relações existem entre as qualidades reais do objeto, responsáveis pela percepção estética e, em segundo lugar, em identificar e definir o caráter da ligação entre o funcionamento da natureza humana do sujeito que percebe e as qualidades do mundo real que são percebidas. Duas palavras podem ser lembradas para exprimir essa última tensão: de um lado, a beleza, de outro, o gosto. Na realidade, essas são duas categorias bastante amplas e que permitem considerar a descrição das relações entre o indivíduo que sente e aquilo que é sentido. Por um lado, a beleza parece se referir às qualidades de um objeto. Por outro, o gosto parece se referir à faculdade ou capacidade que o indivíduo tem de perceber essas qualidades. Em todo o caso, é dessa maneira que certa tradição filosófica do século XVIII, da qual Hutcheson faz parte, concebe essa relação. Sua originalidade reside notadamente em seu proce-

2 Foi o filósofo alemão Baumgarten, em 1735, quem empregou a palavra estética pela primeira vez em sua obra Meditações filosóficas sobre alguns tópicos relacionados à essência do poema (publicado em latim com o título Meditationes philosophicae de nonnullis ad poema pertinenbus). Tratava-se de dar nome a um novo campo de pesquisa para a filosofia, um campo que, segundo o autor, se delineava ao longo de seus desenvolvimentos sobre a poética filosófica, mas que se definia cada vez mais como "ciência que dirige a faculdade de conhecimento inferior, ou ainda uma ciência do mundo sensível do conhecimento de um objeto". Ele parte das distinções da Grécia antiga entre $\alpha i \sigma \theta \eta \tau \alpha \dot{~(a s ~ c o i s a s ~ s e n s i ́ v e i s, ~ o b j e t o s ~ d a ~ s e n s a c ̧ a ̃ o, ~ m a s ~ t a m b e ́ m ~ o b j e t o s ~ d a ~}$

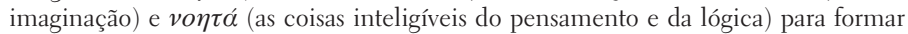

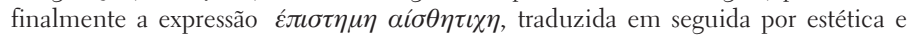
que busca dar conta das coisas relativas à percepção sensível. Contudo, a aparição do nome não marca por si só a aparição do campo de pesquisa que lhe corresponde. $\mathrm{Na}$ verdade, o uso desse termo virá mais para completar um processo de evolução e de pesquisa que lhe precede, processo no qual Francis Hutcheson tem seu lugar. Para a origem do termo estética e seu uso por Baumgarten, ver a introdução de S. Trottein em L'Esthétique naît-elle au XVIIIe siècle? Paris: PUF, 2000. No que diz respeito a Baumgarten, ver: Baumgarten, A. G. Esthétique, précédée des Méditations philosophiques sur quelques sujets se rapportant à l'essence du poème et de la Métaphysique. J.Y. Pranchère (trad.), Paris: L'Herne, "Bibliothèque de philosophie et d'esthétique", 1928. 
dimento: ele se inspira nos métodos de pesquisa filosófica desenvolvidos por Locke para conceber sistematicamente um campo da filosofia até então pouco explorado desse modo, qual seja, o da teoria da beleza. De fato, é a partir da relação entre um objeto visível e a formação das ideias na mente humana que Hutcheson conceberá a articulação entre gosto e beleza. Hutcheson revela assim a chave de sua teoria estética: a defesa da existência de um sentido natural da beleza. O tratado dedicado ao senso de beleza e o tratado dedicado à moral não estão reunidos por acaso: trata-se de uma só e mesma investigação. ${ }^{3} \mathrm{O}$ objeto principal da filosofia de Hutcheson é demonstrar a existência de um senso moral no homem, princípio determinante da natureza humana, capaz de fazer o indivíduo se interessar por outros e se abrir ao mundo exterior. É, portanto, em resposta a Mandeville que Hutcheson elabora seu sistema. A consequência importante do senso moral é tornar o indivíduo por natureza sociável e sensível ao interesse do outro. O indivíduo que calcula racionalmente visando seu interesse pessoal é também o indivíduo que sente e percebe, que se sensibiliza frente ao prazer e à dor do outro. Hutcheson considera que o senso moral será mais facilmente aceito se, logo de início, ele apresentar o homem como detentor de outra sensibilidade

3 Isso não significa, contudo, que o senso de beleza e o senso moral não sejam dois sentidos distintos. Há uma analogia de funcionamento entre esses dois sentidos, que são nomeados "internos" em oposição aos sentidos externos (os cinco sentidos). O senso moral pode ser considerado como o sexto sentido, já o senso de beleza seria o sétimo (ou inversamente). O senso moral é uma sensibilidade natural que reage à percepção da relação de qualidades objetivas que suscitam em nós a ideia da virtude ou do vício. A ideia da virtude é acompanhada de prazer, a ideia do vício é acompanhada de sofrimento. O senso de beleza é uma sensibilidade natural que reage à percepção da relação de qualidades objetivas que suscitam em nós a ideia da beleza ou a ideia da feiura. A ideia da beleza é acompanhada de prazer, a ideia da feiura é acompanhada de sofrimento. $\mathrm{O}$ prazer ligado à ideia da beleza não é o mesmo que o prazer ligado à ideia da virtude. $\mathrm{O}$ mesmo ocorre com o sofrimento ligado à ideia da feiura e o sofrimento ligado à ideia do vício. No entanto, o ponto em comum que une a ideia da beleza acompanhada de prazer e a ideia da virtude acompanhada de prazer é o desinteresse, ou mais simplesmente, a ausência de considerações de interesse pessoal. Assim que entra em cena, o interesse pessoal impede a ambos, senso de beleza e senso moral, de funcionar corretamente. 
natural: aquela da beleza. Em outras palavras, uma vez aceito o senso de beleza, será mais fácil admitir um senso moral. Com efeito, Hutcheson considera que o senso de beleza tem a vantagem de poder facilmente ser distinguido do cálculo racional, além de poder ser aproximado de uma forma de sensibilidade. Trata-se de uma base sólida para demonstrar o caráter desinteressado de um dos princípios determinantes do funcionamento da natureza humana. Ele não pode, de modo algum, ser aproximado ao funcionamento de um cálculo racional visando a satisfação do interesse pessoal de um homem. ${ }^{4}$ Da mesma forma, o senso de beleza serve para demonstrar a igualdade natural dos indivíduos a partir de uma faculdade ou capacidade que todos possuem desde o nascimento. Ele é, por fim, um ponto de partida possível para conceber a existência de Deus a partir daquilo que é percebido como belo no mundo. É esse último ponto em particular que vai nos interessar. O próprio título do primeiro tratado parece estabelecer uma relação e talvez mesmo uma gradação: "a beleza, a ordem, a harmonia e o desígnio”. Em outras palavras, pode-se passar da beleza à ordem, da ordem à harmonia, da harmonia ao desígnio? Pode-se ter acesso à prova ou às provas da existência de Deus a partir de uma experiência estética?

\section{Quadro da experiência}

\section{A. Raciocínio e sensibilidade}

São essas as questões que Hutcheson levanta, particularmente na seção 5 e em certas partes da seção 8 do primeiro tratado de sua Investigação. Mais precisamente, ele dedica o fim da seção 4 e a totalidade da seção 5 a argumentos em favor do desígnio. Ele

\footnotetext{
4 Hutcheson não considera o senso de beleza como um "bom senso" ou um "senso comum” racionais. O senso de beleza é uma sensibilidade imediata, involuntária e natural do ser humano. Segundo certa analogia, o senso de beleza pode ser aproximado do funcionamento dos cinco sentidos externos, tal como na visão, na audição, no olfato, no paladar e no tato. A razão não intervém nesse processo. (Hutcheson, 1991, p. 42).
} 
busca assim demonstrar como é possível conceber a existência de um desígnio no universo a partir da experiência de nossas sensações, de nossa imaginação e da reflexão sobre nossas ideias, provenientes da sensação. Alguns dos argumentos físico-teológicos utilizados por ele fazem apelo à razão e não ao senso de beleza. É pelo raciocínio que, em suas próprias palavras, "parece quase demonstrado que há um desígnio no universo"s (Hutcheson, 1991, p. 93). No entanto, "parecer quase demonstrar" não é "demonstrar”. Hutcheson propõe-se então a raciocinar a partir da experiência e de nossa imaginação para colocar a questão a respeito da probabilidade de uma hipótese. O problema dos argumentos físico-teológicos que fazem apelo ao raciocínio é que eles não permitem verdadeiramente ultrapassar a simples possibilidade. Não são razões suficientes para acreditar. Na medida em que nos falta uma série de dados, para que uma hipótese seja provável e engaje a convicção é preciso algo mais. Podemos nos apoiar sobre nossa experiência e sobre nossa imaginação através da sensibilidade. Em primeiro lugar, portanto, o homem parte de sua experiência pessoal, dos conhecimentos intuitivos que ele adquire. Por exemplo, existe uma experiência intuitiva que pode prover acesso a certas considerações em prol do desígnio. E o interessante dessa experiência é que ela não é reservada a um pequeno grupo de eleitos: todos os homens possuem em si mesmo essa faculdade natural e todos podem ter acesso às mesmas condições de experiência. Em seu Ensaio sobre a natureza e a conduta das paixões e afecções, de 1728, Hutcheson explica em maiores detalhes:

Sobre a conduta de nosso sentido interno, devemos observar um de seus efeitos naturais, a saber, que ele nos conduz à apreensão de uma divin-

5 Mobilisando o argumento das "dessemelhanças" entre os animais para rejeitar o postulado, de Descartes e Epicuro, de uma força sem direção que age sobre uma matéria infinita, Hutcheson conclui na Investigação: "and seems almost a demonstration of design in the universe." (Hutcheson, 1725/26, p. 93). 
dade. A grandeza, a beleza, a ordem, a harmonia, onde quer que se produzam, suscitam a opinião de uma mente, do desígnio e da sabedoria. Qualquer coisa grande, regular ou bem proporcionada excita a veneração, seja em direção à própria coisa, se a imaginamos animada, seja em direção a qualquer causa apreendida, se a imaginamos inanimada. Nenhuma determinação de nossa mente é mais natural que essa, nenhum efeito mais universal. ${ }^{6}$ (Id., 1728 , p. 175)

É dessa forma que o desígnio é introduzido na filosofia estética de Hutcheson. Apreender uma divindade é um dos efeitos naturais produzidos pelo uso de nosso sentido interno da beleza. Trata-se de uma questão de sensibilidade e de experiência que se inscreve no curso natural das coisas, na determinação da natureza humana em pensar dessa maneira. Mesmo que essa determinação não seja a própria crença, mas a constatação de grandeza, beleza, ordem e harmonia por todo o mundo. E essa constatação provoca admiração, por vezes inclusive veneração. A veneração, por sua vez, toca tanto o objeto quanto a causa provável desse objeto. Trata-se aqui menos de interrogar-se a respeito dos argumentos físico-teológicos que sobre o senso de beleza e o papel que esse último desempenha no desenvolvimento de certos argumentos a favor do desígnio: como uma experiência sensível pode engendrar uma convicção no homem, uma convicção sobre a causa final do universo? Do mesmo modo, não se trata de cogitar como a ideia de beleza relativa e a ideia de beleza absoluta em relação ao desígnio podem contribuir a essa experiência. A questão está menos no raciocínio que na sensibilidade. É na maneira pela qual uma ideia se forma na mente que a experiência pode se manifestar em

6 "Under this head of our internal sense, we must observe one natural effect of it, that it leads us into apprehensions of a deity. Grandeur, beauty, order, harmony, wherever they occur, raise an opinion of a mind, of design, and wisdom. Every thing great, regular, or proportioned, excites veneration, either toward itself, if we imagine it animated, if not animated, toward some apprehend cause. No determination of our mind is more natural than this, no effect more universal." (Hutcheson, 1728, p. 175). 
sua forma mais simples e natural, no caso uma ideia produzida a partir da percepção de nosso sentido interno da beleza. Essa ideia não se forma sem analogia ou semelhança com nós mesmos, ou ainda, nossas ideias da beleza relativa e da beleza absoluta podem desempenhar um papel nessa direção.

O senso de beleza nos provê acesso a uma forma de conhecimento intuitiva: imediata, involuntária e certa. De fato, como em Locke, nossas percepções e nossa reflexão constituem a base de nossa experiência e, portanto, de nosso conhecimento. ${ }^{7}$ A diferença, no que tange à sensação, é que Hutcheson alarga o campo de nossas percepções com dois novos sentidos que são os sentidos internos da beleza e da moral. As percepções desses sentidos tocam nossa mente e estão na origem de algumas de nossas ideias. No caso que nos interessa, o de nosso senso de beleza, temos uma experiência individual mas que se reproduz universalmente de acordo com o mesmo mecanismo: são as mesmas qualidades que provocam a mesma ideia de beleza em todos os seres humanos. Hutcheson estima que a ideia da beleza em um homem nasce da mesma maneira e remete à mesma experiência que a ideia de beleza em outro homem. Em outras palavras, todos os seres humanos são sensíveis às mesmas qualidades e formam a mesma ideia da beleza frente a essas qualidades. ${ }^{8}$ É dessa forma, por exemplo, que

7 "Ce sont là, à mon avis, les seuls principes d'où toutes nos idées tirent leur origine; savoir, les choses extérieures et matérielles qui sont les objets de la sensation, et les opérations de notre esprit qui sont les objets de la réflexion" (Locke, Essai philosophique concernant l'entendement humain. Paris: Vrin, 1972. Réédition de la $5^{\mathrm{e}}$ édition de la traduction Coste par E. Naert, II, I, \$1-5 p. 61-62). No original, em inglês: "These two, I say, viz. External material things, as the objects of sensation, and the operations of our own minds within, as the objects of reflection, are to me the only originals from whence all our ideas take their beginnings" (adição do tradutor).

8 Hutcheson explica as "diferenças" de "julgamento" estético entre os homens como o resultado das associações de ideias. As associações podem obscurecer e perverter a percepção do senso de beleza. Sem o parasitismo das associações de ideias, o senso de beleza funciona da mesma maneira para todos: há, portanto, universalidade no juízo estético. É por essa razão, ademais, que a obra de arte é melhor apreciada em um espaço neutro, sem interferências externas. Pode-se pensar no espaço de um museu para ilustrar essa teoria: ele oferece as condições ideais para o exercício de nosso sentido estético porque as associações de ideias têm pouco espaço para se exercer ali. A obra 
Hutcheson rejeita o puro subjetivismo estético: o que é percebido como belo o é para todos. Mesmo que a beleza seja uma ideia, é uma ideia sobre a qual os homens estão de acordo, uma vez que ela deve responder a um fenômeno exterior à mente humana. Em outro plano, contudo, mesmo admitindo que a beleza não seja mais que uma ideia da mente humana, é uma ideia aprazível a todos os homens. O fato de que todos os homens associem à ideia da beleza um mesmo prazer estético demonstra para Hutcheson, certa uniformidade e certa sensibilidade humana comum a todos. Por que os homens funcionam da mesma maneira? Por que todos têm a mesma relação com a mesma ideia?

\section{B. Experiência, probabilidade e convicção}

Hutcheson não afirma que a experiência estética deve conduzir a uma prova propriamente dita da existência de Deus. Trata-se apenas de mostrar que a experiência do mundo, por meio da percepção do senso de beleza, pode conduzir à ideia da existência de Deus. Permanecemos no campo da probabilidade. Uma forte probabilidade pode causar adesão e convicção no homem. Duas coisas estão em jogo: de um lado, a relação entre nossa ideia da beleza do mundo e nossa ideia da existência de Deus; de outro, a relação entre nossa ideia da existência de Deus e essa existência real. Hutcheson explica que a ideia da existência de Deus provavelmente corresponde a alguma coisa de real no mundo; resta saber qual o grau de correspondência que há entre ideia e realidade. Toda a questão da investigação empírica consiste em saber quais conclusões tirar dessas relações. De fato, a ideia da existência de Deus não é uma ideia que surge diretamente da percepção de nosso senso de beleza. A partir da ideia 
produzida pelo nosso senso de beleza, e de maneira mais ampla, a partir de nossas ideias de beleza, uma reflexão é lançada. É preciso refletir sobre as ideias de beleza que formamos na mente no intuito de poder engajar a reflexão sobre a relação que essas ideias de beleza têm com a ideia da existência de Deus. Apesar disso, esse trajeto é individual e pessoal, não constituindo a base de um ensino ou as premissas de uma demonstração científica. No entanto, uma demonstração científica não é sempre indispensável para que um homem atinja a convicção. Nossos raciocínios são capazes de analisar as relações entre nossas ideias de modo a determinar com qual grau de certeza uma experiência estética pode estar associada à ideia da existência de Deus. Isso não implica obrigatoriamente que a realidade e nossas ideias se correspondam perfeitamente. Ao contrário, certo grau de correspondência entre ideias e a realidade podem bastar para convencer o homem que ele detém certa forma de conhecimento pela experiência. Não um conhecimento certo, de tipo científico, e sim um conhecimento baseado na probabilidade mas ainda assim suficiente para que o homem não duvide dele. No caso da ideia da existência de Deus, trata-se de demonstrar ao mesmo tempo que a ideia dessa existência pode remeter a uma experiência de alguma coisa na realidade, mesmo que essa coisa não seja a existência de Deus, mas uma experiência à qual somos sensíveis e que nos incita a pensar em sua causa final. É algo dessa natureza que Hutcheson quer mostrar com a ideia da beleza. Essa ideia corresponde a algo real, mas essa realidade não é a própria beleza. A diferença é que, para a ideia da existência de Deus, há qualidades reais do mundo que podem ser interpretadas como signos de uma causa que, provavelmente, é a existência de um artesão divino - mesmo que essa existência não seja demonstrável e não possa constituir um conhecimento certo. Em todo o caso, todo indivíduo racional e sensível possui a faculdade de sentir e depois a de raciocinar, partindo da ideia da beleza para se aproximar da ideia do desígnio, mesmo que, não 
custa lembrar, não se trate de uma obrigação, mas de um trajeto pessoal. Quando conjectura sobre argumentos físico-teológicos, Hutcheson os considera não em relação ao conhecimento científico de Deus, mas a uma experiência que nos permite "acreditar", ou mais simplesmente, de sentir certo número de relações entre um todo e suas partes, entre uma ideia e outra, entre uma ideia e o mundo real. Ele leva sua investigação até o que lhe parece ser os limites do entendimento da natureza humana. Os argumentos físico-teológicos que ele emprega, de certa maneira, mobilizam o conjunto de sua teoria estética. A experiência estética pode conduzir a conceber o mundo em relação à sua causa racional a partir da harmonia que ali reina; e ao fazê-lo, consideramos a causa racional do mundo como uma ideia. Mais, essa ideia nos é acessível pela observação do mundo real. Para Hutcheson, a percepção é sempre percepção de alguma coisa, e ignorar essa "alguma coisa" não significa dizer que ela não exista. ${ }^{9}$ As percepções que não remetem a alguma realidade do mundo exterior simplesmente não são percepções. A percepção nos fornece um acesso a algo e, portanto, é um ponto de partida para analisá-lo; seja explorar um objeto ou refletir sobre a causa desse objeto. A questão da prova da existência de Deus exige assim uma investigação empírica, com o intuito de compreender o que se trata e quais são as relações em jogo.

9 Apesar de não se tratar da mesma discussão, Leibniz dirigia essa crítica a Descartes: “je ne vois pas l'avantage de considérer comme faux ce qui est douteux: ce ne serait pas se délivrer des préjugés, on ne ferait qu'en changer” (Leibniz, G. Remarques sur Descartes. Opuscules philosophiques choisis. Paris : Vrin, 2001, p. 35). Não publicada durante a vida de Hutcheson, essa afirmação resume bem, em outro contexto, o que ele tenta demonstrar aqui: declarar falso o que é duvidoso definitivamente não é o melhor método de investigação filosófica, significa pôr fim à reflexão antes de ter verdadeiramente começado. A ausência de prova científica da existência de Deus não deve impedir conceber essa existência, experimentála e, eventualmente, acreditar nela. 


\section{A experiência: conceber o desígnio a partir do senso de beleza}

\section{A. As ideias da beleza e a experiência da harmonia}

Para Hutcheson existem duas ideias de beleza capazes de serem formadas na mente humana. A primeira é a ideia da beleza absoluta, a segunda a ideia da beleza relativa. Ele as define assim:

Entendemos, pois, por beleza absoluta apenas aquela beleza que percebemos nos objetos sem os comparar com qualquer coisa externa, em relação à qual se supõe que o objeto seria uma imitação ou imagem, como aquela beleza que percebemos nas obras da natureza, nas formas artificiais, nas figuras e nos teoremas. A beleza relativa ou comparativa é aquela que percebemos nos objetos geralmente considerados como imitações ou semelhantes à outra coisa..$^{10}$ (Hutcheson, 1991, p. 60).

A beleza relativa é a beleza imitativa que consiste na semelhança, melhor ou pior, alcançada entre um objeto e seu modelo. Ela exige, portanto, um ponto de comparação para poder existir. A beleza absoluta, definida acima em seu sentido negativo, é considerada, em seu sentido positivo, como a relação de equilíbrio percebida entre duas qualidades presentes nos objetos: a uniformidade e a variedade. Essa relação entre a uniformidade e a variedade é o que é percebido pelo senso de beleza, na própria percepção dos sentidos externos. ${ }^{11}$ Hutcheson explica que "a be-

10 "We therefore by absolute beauty understand only that beauty, which we perceive in objects without comparison to any thing external, of which the object is suppos'd an imitation, or picture; such as that beauty perceiv'd from the works of nature, artificial forms, figures, theorems. Comparative or relative beauty is that which we perceive in objects, commonly considered as imitations or resemblances of something else." (Hutcheson, 1725/26, p. 14).

11 É uma percepção na percepção. Os sentidos externos (visão, audição, tato, paladar, olfato) percebem duas qualidades presentes no mesmo objeto: uniformidade e variedade. O sentido interno da beleza percebe nas percepções dos sentidos externos a relação de equilíbrio entre essas duas qualidades e esse equilíbrio percebido está na origem da formação de nossa ideia de beleza, ideia acompanhada por prazer. A influ- 
leza é sempre relativa ao sentido de alguma mente"12, porque a ideia da beleza depende da relação entre aquele que percebe e o objeto cujas qualidades reais são percebidas. (Ibid., p. 61). A ideia da beleza do homem, por exemplo, poderia não ser partilhada pelos animais. Eles podem, de fato, ter percepções da beleza diferentes das nossas, se admitirmos que seu sentido interno igualmente existe mas que não é feito como o nosso: "eles podem ter sentidos constituídos diferentemente aos do homem e podem ter suas ideias de beleza excitadas por objetos com uma forma completamente diferente". ${ }^{13}$ (Ibid.)

Quando alguém se refere à "beleza absoluta", entende-se que a ideia de beleza de que falamos não é a representação do que quer que seja, mas sim que se trata da ideia de beleza que corresponde à percepção da uniformidade na variedade de um objeto. A beleza é uma ideia que está associada a três tipos de objetos: a natureza, os objetos de arte e os objetos intelectuais. Hutcheson parece sempre privilegiar a beleza da natureza. De fato, toda beleza da natureza pode ser tomada como beleza absoluta. Na verdade, todo objeto da percepção, por exemplo a arte, mas também teoremas matemáticos e princípios científicos, podem ser incluídos na categoria da ideia de beleza absoluta. Por que razão? Porque todo objeto da experiência estética, não importa quão vasta seja ela, é suscetível de conter a qualidade da relação entre uniformidade e variedade que é a causa da beleza absoluta. Talvez seja melhor di-

ência de Locke sobre Hutcheson impele a questionar se as noções lockeanas de ideia simples e de ideia complexa podem ser aplicadas à ideia de beleza hutchesoniana: seria a ideia de beleza em Hutcheson uma ideia complexa no sentido da definição de Locke? Ou devemos considerar que um sentido implica sempre em uma ideia simples? Sobre essa discussão ver Townsend, D. Lockean Aesthetics, Journal of Aesthetics and Art Criticism - 49, 4, 1995. Townsend aborda a questão defendendo que Hutcheson utiliza o vocabulário lockeano mas provendo-lhe um conteúdo diferente. A respeito da questão das qualidades primárias ou secundarias em Locke e na tradição empirista escocesa, ver também Michael, E. Francis Hutcheson on Aesthetic Perception and Aesthetic Pleasure. British Journal of Aesthetics - 24, 3, 1984.

12 "Beauty has always relation to the Sense of some Mind" (Hutcheson, 1725/26, p. 15).

13 "they may have Senses otherwise constituted than those of Men, and may have the Ideas of Beauty excited by Objects of a quite different Form." (Ibid., 1725/26, p. 15). 
zer que todo objeto contém certa relação de uniformidade na variedade. Os objetos mais "uniformes" reduzem essa relação à sua forma mais fraca, do mesmo modo que o fazem os objetos mais "variados". Contudo, parece difícil afirmar que exista um objeto inteiramente uniforme, sem qualquer variedade seja em sua cor, forma, tamanho, arranjo ou estrutura. Do mesmo modo que é difícil afirmar que um objeto tem apenas variedade e nenhuma uniformidade. A estrutura do mundo é, de modo geral, fundada sempre sobre uniformidade e variedade, bem como sobre algum grau de mistura entre elas. É preciso uma relação particular de equilíbrio entre elas para fazer com que se perceba em um objeto a ideia de beleza e nem todos os objetos contêm esse equilíbrio.

$\mathrm{O}$ fato de que alguns objetos contenham esse equilíbrio pode nos levar à constatação de que há alguma forma de harmonia no mundo. Nessa constatação a uniformidade inspira uma reflexão, porque remete à coesão da natureza e a natureza é coerente visto que ela comporta certo número de signos potenciais dessa coerência. A uniformidade no mundo é um exemplo: poderia ser explicada como a manifestação da intenção de nosso Criador, Ele mesmo estando na origem do desígnio. Eis uma explicação possível, da mesma forma que outras. Contudo, para Hutcheson trata-se de uma explicação que pode facilmente levar à convicção. O senso de beleza permite sentir a uniformidade no mundo e de se sentir em acordo ou, em outras palavras, em "harmonia" com o mundo criado. É dessa maneira que a bondade divina nos pode ser revelada. Seguindo a mesma ideia, Hutcheson escreve em sua Curta introdução à filosofia moral, publicada em 1747:

Todos que acreditam que esse universo, e a natureza humana em particular, foram criados pela sabedoria e pela intenção de uma divindade, devem esperar encontrar em nossa estrutura e armação algumas evidências claras, mostrando as atividades próprias à humanidade, que curso de vida, que funções nos são fornecidas pela providência e sabedoria de nosso Criador, 
e quais são 'por consequência' os meios apropriados à nossa felicidade. ${ }^{14}$ (Id., 1747, p. 2)

Isso é tanto mais impressionante uma vez que o mundo exterior testemunha a relação perfeita de equilíbrio entre uniformidade e variedade, relação que está na origem de nossa ideia de beleza. O que observamos no mundo é certa variedade e, apesar dela, a uniformidade se destaca sempre. Em determinados momentos, em determinados objetos, é a relação de equilíbrio entre uniformidade e variedade que é observada. Todas as nossas experiências do mundo, portanto, impelem-nos a refletir sobre causas. Mas como e por quê? Por ora, é preciso deixar claro que Hutcheson parte de uma mente que acredita em Deus, no sentido acima discutido. É para uma mente que acredita que se abre, a partir da harmonia, a possibilidade de provas claras da existência de uma divindade no mundo; o que não significa que a mente que não acredita não possa fazer um dia o mesmo trajeto. Hutcheson considera duas possibilidades: a experiência de quem acredita e de quem não acredita. $\mathrm{O}$ valor estético pode ser reconhecido por si só ou ser igualmente reconhecido como parte integrante do desígnio. Para uma mente que já acredita, o valor corresponde à excelência do objeto que se integra à excelência do desígnio. Para uma mente que não acredita, o valor pode apenas levar à conjectura dessa ideia. Contudo, o que é percebido pelo homem como estando ordenado poderia ser percebido por outro ser vivo como não o sendo; o que faz com que, em suas palavras, para alguns animais, um punhado de seixos lançados ao acaso seja o local ideal para um habitat. Para Hutcheson, se refletirmos, a hipótese de beleza, de ordem no mundo criada pelo acaso, permanece

14 "All such as believe that this universe, and human nature in particular, was formed by the wisdom and counsel of a Deity, must expect to find in our structure and frame some clear evidences, shewing the proper business of mankind, for what course of life, what offices we are furnished by the providence and wisdom of our Creator, and what $<$ therefore $>$ are the proper means of happiness." (Hutcheson, 1747, p. 2). 
menos provável que aquela da criação segundo a intenção de um criador; e isso porque nossa experiência sensível nos faz sentir que há um todo do qual nós podemos ser parte. A propósito do plano racional, ele afirma que, quando pensamos na natureza e nos elementos, vemos que se trata de mecanismos muito elaborados e complexos. Seria surpreendente se eles tivessem sido elaborados por acaso uma vez que nossa experiência nos demonstra que mecanismos altamente elaborados e complexos não se formam jamais por conta própria. Nosso sentimento nos impele a acreditar que aquilo que experimentamos ultrapassa o simples fruto do acaso: não há, portanto, hipóteses impossíveis, mas há uma hipótese provável que sempre se impõe sobre as outras. Nesse caso, de acordo com Hutcheson, a hipótese do artesão divino se imporia. Todavia, isso mostra bem como tudo depende da mente que percebe e que pensa.

Duas possibilidades são assim abertas: o valor estético pode ter um fim em si mesmo, mas pode também ser o meio através do qual o raciocínio e a sensibilidade atingem a compreensão ou o sentimento da excelência de um desígnio no universo. Para alguém que acredita, a existência de Deus pode ser uma das chaves da estética, na medida em que tudo repousa sobre a perfeição da criação. Ademais, essa descoberta implica tanto a beleza dita absoluta quanto a beleza dita relativa. Tentemos ver como.

\section{B. Da subordinação da beleza relativa à argumentação do desígnio}

A importância do conceito de imitação na estética em Hutcheson foi estudada por Laurent Jaffro. ${ }^{15}$ Como vimos, esse conceito aparece através do que Hutcheson define como beleza relativa. Jaffro explica que é a partir desse conceito que a su-

15 Jaffro, Transformation du concept d'imitation de Francis Hutcheson à Adam Smith, in Naissance de l'esthétique au XVIIIe siècle, dir. S. Trottein. Paris: PUF, 2000, p. 9-51. 
bordinação da teoria estética à outra teoria é possível. Aqui, é na perspectiva do desígnio que pensamos: é sob a ideia da divindade criadora e arquiteta do mundo que a teoria estética pode ser compreendida: a perspectiva físico-teológica se junta a uma perspectiva na qual a arte é produto de uma intenção, de um desígnio. A partir desse ponto de vista, a estética não será mais uma disciplina completamente autônoma. A beleza relativa abre a possibilidade de que um objeto remeta a outro, isto é, de que ele signifique outra coisa que não ele mesmo através da simples semelhança ou da semelhança devida à imitação. Hutcheson se refere à beleza dos animais pela sua uniformidade e pela "unidade de mecanismo" que os definem, individualmente ou no seio de sua espécie (Id., 1991, p. 66). ${ }^{16}$ Há uniformidade entre as diferentes partes de seus corpos, há uniformidade em seu movimento. No plano da espécie, há uniformidade através da semelhança que os une, há unidade no seio dessa variedade. O mesmo ocorre na natureza e suas "partes inanimadas" (Ibid., p. 96). ${ }^{17}$ A unidade do conjunto, a uniformidade na variedade, presente tanto nas partes quando no todo, oferece-nos um espetáculo único: um espetáculo que remete à ideia de um criador porque demonstra a que ponto as coisas são bem feitas. Jaffro explica então que o mecanismo da natureza demonstra como podemos ter o maior número de efeitos com os elementos mais econômicos. De fato, Hutcheson afirma:

A beleza que resulta do mecanismo aparentemente adaptado às necessidades e às vantagens de um animal qualquer, mecanismo que nos agrada mesmo que não retiremos dele nenhuma vantagem, será considerada sob o nome de beleza relativa ou desígnio. ${ }^{18}$ (Ibid., p. 67)

16 Hutcheson, $1725 / 26$, p. 22.

17 Hutcheson, $1725 / 26$, p. 63 .

18 "The Beauty arising from Mechanism, apparently adapted to the Necessitys and Advantages of any Animal; which pleases us, even tho there be no Advantage to our selves ensuing from it; will be consider'd under the Head of Relative Beauty, or Design." (Hutcheson, 1725/26, p. 24) 
É posto assim em evidência uma ligação entre a observação de um mecanismo, a beleza relativa e o desígnio. O que isso implica?

Passamos aqui da constatação da uniformidade, da regularidade, da eficácia de um mecanismo à perspectiva da beleza relativa. O mecanismo da natureza remete à intenção de um criador, de uma divindade arquiteta ou artesã, mas apenas o mecanismo não é suficiente, também é preciso a ideia agradável, o prazer positivo ligado à percepção desse desígnio, de um desígnio benevolente por trás de tudo. Em outras palavras, as leis gerais que se aplicam à natureza podem se tornar evidência de um desígnio, de uma intenção divina. Assim se opera aqui um deslizamento da percepção humana à razão pela qual há beleza no mundo, ou melhor, à razão pela qual essas qualidades que suscitam a ideia de beleza em nós existem no mundo. Chegamos assim a pensar na ou nas causas. Laurent Jaffro insiste que o conceito de imitação, que está na base da beleza relativa, segundo essa tradição, permite pensar em termos de cópia, mas ao mesmo tempo em termos de signos de uma intencionalidade na representação. Do mesmo modo que a mente pode ver na natureza uma semelhança com um traço moral, a mente vê os elementos naturais como semelhantes, ou melhor, exprimindo a semelhança com o homem: uma tempestade no mar se assemelha à cólera, por exemplo. O homem é capaz de ir mais longe e passar da constatação de uma semelhança entre um objeto e outro à ideia da imitação do primeiro pelo segundo e, portanto, à ideia de um artesão a fabricar essa imitação, vale dizer, à causa. Como se a imitação fosse o signo da intenção de um artesão que se esconde por detrás dela; eis o que a visão da arte permite fazer. A natureza pode ser vista como uma obra de arte. Vê-se assim onde a questão da estética se distingue da questão da arte: a ideia da beleza em si mesma não conduz necessariamente à intenção de um criador. Contudo, a imitação de um modelo remete ao artesão, e essa via é acessível através da beleza relativa, 
onde a ideia de correspondência com a intenção de um artesão é uma das aplicações possíveis. A partir do momento em que o homem tem ideias de beleza relativa a respeito da natureza, uma perspectiva se abre. A beleza relativa permite o desenvolvimento de argumentos físico-teológicos:

Aos observadores curiosos, essa beleza que nasce da correspondência com uma intenção abriria uma nova perspectiva nas obras da natureza, se eles considerassem como o mecanismo das diferentes partes que nos são conhecidas parece se adaptar com perfeição a cada uma delas, e ainda está subordinado ao bem de algum sistema ou do todo. Geralmente supomos que o bem da maior quantidade ou de todos os seres teria sido a intenção do autor da natureza, e não podemos nos impedir de nos sentirmos satisfeitos em ver uma parte desse desígnio executado nos sistemas com os quais estamos familiarizados. ${ }^{19}$ (Ibid., p. 81 )

O ponto importante é que tudo aquilo que poderia ser visto como beleza absoluta na natureza, se transforma, na verdade, em beleza relativa, na medida em que é relacionado ao desígnio e à intenção do Criador. Não há mais beleza absoluta, há somente evidências da inscrição do mundo no desígnio.

Há meios, todavia, de matizar essa constatação. Assim como a ideia de beleza absoluta, a ideia de beleza relativa depende da percepção de uma mente. Um objeto que comporta a beleza absoluta pode igualmente suscitar a constatação da beleza relativa, se a mente a perceber em função de uma imitação ou uma semelhança frente a outro objeto. Tudo depende da maneira como

19 "This Beauty arising from Correspondence to Intention, would open to curious Observers a new Scene of Beauty in the works of NATURE, by considering how the Mechanism of the various Parts known to us seems adapted to the Perfection of that Part, and yet in Subordination to the Good of some System or Whole. We generally suppose the Good of the greatest Whole, or of all Beings, to have been the Intention of the AUTHOR of Nature; and cannot avoid being pleas'd when we see any part of this Design executed in the Systems we are acquainted with." (Ibid., 1725/26, p. 40) 
a relação toma posição entre mente e objeto. Uma mente que crê, como a de Hutcheson, sente a intenção através da relação que ela entrevê na beleza da natureza. Trata-se de uma percepção que não terá lugar em uma mente que não acredita em Deus; a essa restará então a beleza absoluta dessa mesma natureza. A teoria estética de Hutcheson foi concebida de tal modo que os dois casos são possíveis. A beleza relativa, no final das contas, não traduz mais que o trabalho da imaginação e da reflexão associadas tanto à sensibilidade quanto ao desejo da mente de estabelecer comparações e relações entre as coisas que a circundam, um desejo de identificar e de incluir os fenômenos naquilo que é conhecido. Esse gosto de "trazer para si” o mundo e o universo é propriamente humano e não há nenhuma razão para limitá-lo. Engloba natureza e universo colocando ali uma intenção. É uma tendência de nossa própria natureza. Se a veracidade dessas relações não pode ser demonstrada, tampouco o pode ser sua falsidade. Vimos bem que o passo a ser dado entre a ideia de uma causa inteligente e sábia do mundo e a realidade existente dessa causa pertence apenas à mente que pensa. Eis que nos defrontamos novamente com a seguinte constatação: a probabilidade na ideia da causa pode nos fazer aderir à crença da realidade dessa causa. Tal crença certamente não é demonstrável, mas está longe de ser sem fundamento. Nosso autor aponta assim, logicamente, o que para ele é uma extensão possível de sua estética e de sua teoria da arte através da beleza relativa. Contudo, não se trata de uma extensão obrigatória e inevitável, ainda que uma mente atenta deva poder considerar o desígnio a partir de seu próprio senso de beleza apenas. Pondo de lado a questão da adesão ou não à crença, conceber a relação entre a ideia da beleza relativa e a ideia da divindade é algo que, portanto, todos devem ser capazes de fazer. Já a crença na existência de Deus, isto é, a passagem da ideia à crença de sua correspondência na realidade, é um tópico delicado e depende da relação de cada um com sua própria existência. 


\section{Da subordinação da beleza absoluta à argumentação do desígnio}

Se a subordinação da teoria estética de Hutcheson ao argumento do desígnio passa pela ideia da beleza relativa, trata-se então de uma subordinação apenas parcial. Uma subordinação à qual escapa a ideia da beleza propriamente dita, a beleza absoluta. Se a beleza absoluta lhe escapa, o senso de beleza, que constitui o centro da teoria hutchesoniana da beleza, igualmente lhe escapa. Contudo, como vimos com a questão da harmonia, nada é tão simples. Adicionaremos, pois, outra consideração. Assim como a beleza relativa pode ter precedência sobre a beleza absoluta, para fazer a ligação com o argumento do desígnio, o raciocínio inverso também é possível. Como? Na medida em que a semelhança e o conceito de imitação estão na base da beleza relativa, podem ser considerados como fundados em um tipo de unidade, de coerência ou de aproximação, que nos permite agrupá-los sob o conceito de uniformidade. Trata-se de uma forma de uniformidade entre as qualidades de um modelo e as qualidades de sua imitação que define, no final das contas, o valor da imitação. Ou ainda, como o modelo e sua cópia são objetos distintos, podemos apreciá-los, dentro de nosso conceito de beleza relativa, como uma relação de uniformidade no seio da variedade, isto é, semelhança no seio daquilo que é distinto. Nesse caso, retomamos uma consideração da harmonia no mundo em que vivemos, uma harmonia que é, para aquele que crê, evidência de uma causa sábia e inteligente no mundo. Uma harmonia que é, para aquele que não crê, simples associação dessa ideia com a da beleza. Hutcheson se preocupou em elaborar anteriormente uma teoria das percepções que pudesse ser considerada de modo autônomo frente a seus desenvolvimentos teológicos, mesmo que esses últimos viessem a se adicionar à teoria. E de fato, ele pensou também em uma série de passagens ou de relações possíveis entre a ideia da beleza relativa e a de beleza absoluta. Notadamente, é por essa razão que nossa ideia de beleza relativa não se forma de modo totalmente inde- 
pendente do exercício de nosso senso de beleza. Daí porque a ideia de beleza relativa (através da imitação e da consideração da relação entre artesão e obra de arte) e a ideia da beleza absoluta (e sua consideração da harmonia se destacando da uniformidade na variedade) podem permitir conceber a ideia do desígnio e, portanto, a ideia da existência de Deus.

\section{Prolongamento da experiência: o critério da utilidade}

\section{A. A utilidade}

Vejamos agora como a reflexão sobre o desígnio pode ser desdobrada a partir da consideração da utilidade. Em sua filosofia estética, Hutcheson privilegia sempre um ponto de vista universal em relação à natureza, e se interessa mais pela relação entre objetos que pelos próprios objetos. Por causa disso, essa consideração de um todo pode conduzir a uma reflexão sobre a causa racional do mundo.

Hutcheson pressupõe que, se existisse uma divindade, ela seria sabia e benevolente: ela escolheria nos fazer amar aquilo que nos é vantajoso. Somos, na verdade, limitados. Nosso conhecimento do mundo é incerto demais para conter um largo espectro de verdades particulares; privilegiamos então o conhecimento de causas gerais. A uniformidade é o que melhor corresponde ao nosso limitado entendimento. Podemos considerar que a divindade nos faz preferir aquilo que mais nos convém através do senso de beleza: ele nos conduz na mesma direção que nossa capacidade de compreender e de conhecer. Isso não significa que senso de beleza e poder cognitivo se confundam, quer dizer apenas que Deus nos fez seres coerentes, isto é, que obtemos prazer daquilo que é útil à nossa sobrevivência. Contudo, a utilidade não é critério do senso de beleza. A uniformidade na variedade é o critério da beleza e se descobre que ela é também, indiretamente, um critério que corresponde à necessidade de nosso entendimento. Em outras palavras, um critério daquilo que é suscetível de nos 
trazer a maior felicidade e tem, portanto, certa utilidade para nossa espécie. Sem uniformidade, a variedade nos escaparia. Sem uniformidade não saberíamos nada daquilo que se passa ao nosso redor. Temos aqui a articulação entre o útil e o agradável, com a constatação de que aquilo que é agradável é também útil. Em sua Curta introdução à filosofia moral Hutcheson escreveu a esse respeito:

Pois, pelo sábio artifício de Deus, nossos sentidos e apetites são feitos tendo em vista nossa felicidade, de tal modo que aquilo que eles tomam como imediatamente agradável geralmente é útil em outros planos, seja para nós mesmos, seja para a humanidade. ${ }^{20}$ (Hutcheson, 1747, p. 13-14).

Além disso, a uniformidade impede nossa mente de se "dispersar" ou de se desviar de seu objetivo: o que é uniforme retém nossa atenção e é mais facilmente memorizado. Em um objeto uniforme, não é obrigatoriamente necessário conhecer todas as partes para entender o todo, a uniformidade faz com que, por vezes, uma parte permita conhecer o todo. Provavelmente Deus fez com que nosso interesse estético e utilitário se unissem porque ele quer o que há de melhor para nós. Trata-se de uma simples coincidência? Hutcheson pensa que não. Eis outra hipótese que tira sua validade de sua probabilidade e de nossa própria experiência. Como explicar de outro modo, pergunta-se Hutcheson, que o agradável e o útil se unam? Contudo, é preciso prestar atenção: em geral não estamos conscientes da ligação entre a utilidade e nossa apreciação estética. Na verdade, para que nossa apreciação estética seja bem exercida é preciso que não saibamos que tal ligação exista. Em todo o caso, a investigação da utilidade parasitaria nossa experiência estética: é preciso ter um interesse unicamente

20 "For, by the wise contrivance of God, our senses and appetites are so constituted for our happiness, that what they immediately make grateful is generally on other accounts also useful, either to ourselves or to mankind" (Hutcheson, 1747, p. 13-14). 
estético para atingir a verdadeira ideia da beleza de um objeto e não investigar aquilo que é bonito por seu caráter útil, uma vez que isso não traria os resultados esperados. Talvez seja preciso considerar a questão sob outro ângulo e notar que o denominamos aqui útil está, na realidade, muito afastado do que geralmente é considerado como útil.

\section{B. Contra Berkeley}

Hutcheson mantém efetivamente a distinção entre utilidade e beleza por ocasião de sua resposta a Berkeley e seu Alciphron, de $1732 .{ }^{21}$ Para Berkeley, o sentimento da beleza depende muito claramente do reconhecimento do caráter útil de um objeto. $\mathrm{Na}$ Investigação, Hutcheson busca distinguir a beleza da utilidade mostrando que a utilidade existe nos objetos que não são belos; daí a utilidade não ser beleza. Através de contra exemplos, ele demonstra que a conexão entre beleza e utilidade nunca é direta. Se toda beleza fosse percepção de uma utilidade, então os objetos que não são geralmente considerados belos imediatamente se tornariam belos: uma cadeira, uma cama, uma faca de cozinha. Finalmente, Hutcheson escreve:

Se não tivéssemos um tal senso de beleza e harmonia, casas, jardins, roupas, aparelhos, poderiam nos parecer convenientes, frutíferos, calorosos ou cômodos, mas jamais como belos. E ainda assim nada é mais certo que esses objetos frequentemente nos agradam por razões das mais diferentes em muitas ocasiões.2 (Id., 1991, p. 59)

$21 \mathrm{~A} 4$ a edição da Investigação, datando de $173^{8}$, contém uma resposta ao Alciphron, or The Minute Philosopher publicado em 1732 por Berkeley. Essa confrontação entre os dois filósofos é abordada pelo artigo de Guyer, P. Beauty and Utility in Eighteenth-Century Aesthetics. Eighteenth-Century Studies - 35, 3, 2002. A edição de Berkeley utilizada é a seguinte: Berkeley, G. The Works of George Berkeley. Bishop of Cloyne, A.A. Luce and T.E. Jessop (eds), Londres: Nelson, 1950.

22 "Had we no such sense of beauty and harmony; houses, gardens, dress, equipage might have been recommended to us as convenient, fruitful, warm, easy; but never as beautiful [: and in faces I see nothing that could please us, but liveliness of 
A utilidade do objeto pode nos agradar quando sabemos que ele vai satisfazer a realização de nosso desejo, mas o prazer em questão não é um prazer estético. É preciso diferenciar entre o senso de beleza e tudo o que está envolvido em um cálculo de interesse.

Na verdade, Hutcheson não põe no mesmo plano a utilidade ligada ao nosso conhecimento global e a utilidade propriamente dita. A uniformidade é útil apenas ao favorecer nosso conhecimento. Ela não é útil para nos enriquecer, ou para nos alimentar ou para qualquer outra necessidade da vida cotidiana. A beleza vai no sentido de nossa vantagem na medida em que a uniformidade é melhor para nós e nosso entendimento, mas trata-se de uma utilidade de sentido superior, uma utilidade que será conhecida pela divindade como sendo a verdadeira utilidade para os seres humanos e sua maior felicidade. Todavia, a consideração de utilidade para um indivíduo não tem nada a ver com a uniformidade. O que ele busca é um uso prático, imediato e preciso, é nisso que procuramos a utilidade: ela vem a serviço de nosso interesse privado imediato. E dessa utilidade a beleza se afasta fortemente. É com certa prudência que precisamos considerar a ligação entre a ideia de beleza e a ideia de utilidade; tudo depende de que utilidade se fala. Apenas uma utilidade associada à ideia de beleza permite alimentar a argumentação do desígnio: que a verdadeira utilidade esteja de acordo com o que é agradável pode ser interpretado como o signo, talvez como a prova, de uma causa inteligente e sábia na origem do mundo. Hutcheson coleciona tais sinais a partir de sua reflexão sobre a beleza.

Conclusão: do desígnio subordinado ao senso de beleza e ao

colour, and smoothness of surface:] and yet nothing is more certain, than that all these objects are recommended under quite different views on many occasions". (Hutcheson, 1725/26, p. 13). 


\section{senso de moralidade?}

O senso de beleza de Hutcheson permite então desenvolver uma argumentação em favor da ideia de uma causa inteligente na origem do mundo e a ideia de uma sabedoria a partir da economia de princípios. Contudo, é preciso sublinhar que em vários momentos de sua obra, os argumentos físico-teológicos servem igualmente como argumentos para a defesa da existência do senso de beleza e do senso moral. É preciso então considerar uma inversão de perspectiva. Ainda que a teoria estética de Hutcheson possa servir ao argumento do desígnio no mundo, os argumentos físico-teológicos servem também de justificativa à sua teoria estética - estamos em uma espécie de círculo. Ademais, a teoria estética de Hutcheson justifica outra teoria: a do senso moral. Por que o senso moral é sensível à ideia de virtude? Por que o senso de beleza é sensível à ideia de beleza? Por que as coisas se organizam tão bem? Hutcheson pressupõe que a resposta se encontra na ordem harmoniosa do mundo. E de onde vem essa ordem? De uma causa sábia e inteligente. Como prová-la? Não a provamos, pelo menos não a outros homens. Provamos somente a nós mesmos. Como? Pela experiência, pela certeza do conhecimento perceptivo e por certo esforço de reflexão, associando razão e imaginação. Poderia a ordem harmoniosa do mundo ser o produto de uma mente subjetiva e não da realidade do mundo? Sim, certamente. Contudo, nossa sensibilidade e o raciocínio da probabilidade tendem mais a favor de uma ordem real que de uma ordem inventada a partir do zero: como os homens se colocariam de acordo uns com os outros a respeito de suas ideias de beleza e moralidade? A uniformidade, a regularidade do mundo podem ser as evidências de uma tal relação. A estética é uma passagem permitindo chegar a algumas considerações sobre a questão. Para alguém que crê, o senso de beleza pode ser apreendido como meio de acesso à sabedoria e à inteligência divinas, o todo se manifestando através da consideração do desígnio. Uma vez admitido o desígnio, não se duvida mais do fundamento da existência de um senso 
de beleza e de um senso moral e o argumento do desígnio confirma a coerência do sistema filosófico de Hutcheson. O fato de que o desígnio seja evocado na última seção do primeiro tratado, justamente antes do tratado sobre a moral é um posicionamento estratégico: passa-se do desígnio à demonstração da existência de um senso moral. O corte ao passar do primeiro ao segundo tratado esconde mal esse encadeamento. As provas físico-teológicas devem poder servir aos argumentos em torno da teoria do senso moral: da presença da inteligência e da sabedoria no mundo pode derivar a ideia da presença da inteligência e da sabedoria no ser humano. O suporte teológico é um suporte eficaz e certo para os argumentos em favor dessa extensão da percepção humana. Temos um argumento de autoridade, por assim dizer. Ele explica, a respeito dos objetos estéticos: "a divindade poderia nos ter formado de modo a não sentirmos qualquer prazer [imediato (inclusão da $2^{\mathrm{a}}$ ed.)] vindo de tais objetos". ${ }^{23}$ (Ibid., p. 117).

No entanto, isso seria incompatível com a sabedoria e a bondade e, portanto, a teoria do sentido interno da beleza e aquela do senso moral são teorias que podem corresponder a certa conformidade entre nossas certezas sobre a realidade e nossas ideias. Em todo o caso, Hutcheson demonstra que o homem faz o que pode com o que tem: utiliza todas as possibilidades à sua disposição. Se o senso de beleza pode levar à ideia de Deus, ele pode igualmente se apoiar sobre a ideia de Deus, como também pode ser considerado unicamente em si mesmo. É a experiência pessoal de cada um que é determinante. Hutcheson foi, em todo o caso, extremamente prudente ao não apoiar sua teoria estética e sua teoria moral unicamente sobre argumentos físico-teológicos. Seria um equívoco considerar que a teoria do senso de beleza e a teoria do senso moral não podem ser estudadas sem a relação ao desígnio. A

23 "And possibly the DEITY could have formed us so as to have receiv'd no Pleasure from such Objects...” (Hutcheson, 1725/26, p. 94) 
refutação de sua argumentação em favor da ideia da existência de Deus não põe em questão essas duas teorias, porque, nesse caso, Hutcheson deixa de se apoiar sobre causas finais e traz à cena sua argumentação sobre a observação dos efeitos da experiência sobre nossa sensibilidade estética e sobre nossa sensibilidade moral. Ignorar a origem de nossas percepções não nos impede de perceber. Isso vale tanto para nossas percepções estéticas como para nossas percepções morais. Hutcheson efetivamente previu passagens entre suas diferentes teorias, mas ele nunca as fez completamente dependentes umas das outras. ${ }^{24}$

\section{Bibliografia}

BAUMGARTEN, A. Esthétique, précédée des meditations philosophiques sur quelques sujets se raportant à l'essence du poème et de la méthaphysique. Tradução J. Y. Pranchère, Paris, L'Herne, 1928, p.128.

BERKELEY, G. The work of George Berkeley. Ed. Luce and Jessop. Londres, Nelson, 1950, p. 128.

FENNER, D. E.W. Art in context understanding aesthetic value. Ohio, Ohio University Press, 2008.

GUYER, P. Beauty and Utility in Eighteenth-Century Aesthetics. Eighteenth-Century Studies - 35, 3, 2002.

HUTCHESON, F. An inquiry into the original of our ideas of beauty and virtue; Alterations and additions made in the second edition ot the "Inquiry into beauty and virtue". Londres, J. Darby, for W. and J. Smith, 1725/1726.

. An essay on the nature and conduct of the passions and affections. Londres, J. Darby and T. Browne, for J. Smith and W. Bruce, 1728 .

24 Um grande agradecimento aos professores Laurent Jaffro e Fernão de Oliveira Salles dos Santos Cruz, cujos trabalhos e observações são uma ajuda e uma inspiração preciosas. Esta pesquisa foi conduzida com o apoio do Capes-Cofecub SH 754/12. 
HUTCHESON, F. A Short Introduction to moral philosophy. Glasgow: R. Foulis, 1747 . Recherche sur l'origine de nos idées de la beauté et de la vertu. Anne-Dominique Balmès (traduction). Paris, Vrin, 1991.

JAFFRO, L. Transformation du concept d'imitation de Francis Hutcheson à Adam Smith, in Naissance de l'esthétique au XVIIIe siècle, dir. S. Trottein. Paris, PUF, 2000, p. 9-51.

LEIBINIZ, G. W. "Remarques sur Descartes", in: Opuscules Philosophiques Choisis. Paris, Vrin, 2004.

LOCKE, J. Essai philosophique concernant l'entendement humain. Tradução Pierre Coste. Paris, Vrin, 1972, p. 129.

MICHAEL, E. Francis Hutcheson on aesthetic perception and aesthetic pleasure. British Journal of Aesthetics - 24, 3, 1984.

TOWNSEND, D. Lockean aesthetics. Journal of Aesthetics and Art Criticism - 49, 4, 1995. 